OPEN ACCESS

Edited by:

Ruhong Zhou,

IBM Research, United States

Reviewed by:

Feng Ding,

Clemson University, United States

Pu Chun Ke,

Monash University, Australia

${ }^{*}$ Correspondence:

Guanghong Wei

ghwei@fudan.edu.cn

Specialty section: This article was submitted to

Nanoscience,

a section of the journal

Frontiers in Chemistry

Received: 31 October 2019

Accepted: 16 January 2020

Published: 05 February 2020

Citation:

Bai C, Lao Z, Chen Y, Tang Y and

Wei G (2020) Pristine and

Hydroxylated Fullerenes Prevent the

Aggregation of Human Islet Amyloid

Polypeptide and Display Different

Inhibitory Mechanisms.

Front. Chem. 8:51.

doi: 10.3389/fchem.2020.00051

\section{Pristine and Hydroxylated Fullerenes Prevent the Aggregation of Human Islet Amyloid Polypeptide and Display Different Inhibitory Mechanisms}

\author{
Cuiqin Bai, Zenghui Lao, Yujie Chen, Yiming Tang and Guanghong Wei*
}

State Key Laboratory of Surface Physics, and Key Laboratory for Computational Physical Science (Ministry of Education), Department of Physics, Multiscale Research Institute of Complex Systems, Fudan University, Shanghai, China

Protein aggregation, involving the formation of dimers, oligomers, and fibrils, is associated with many human diseases. Type 2 diabetes is one of the common amyloidosis and linked with the aggregation of human islet amyloid polypeptide (hIAPP). A series of nanoparticles are reported to be able to interact with proteins and enhance/inhibit protein aggregation. However, the effects of $\mathrm{C}_{60}$ (a model system of hydrophobic nanoparticle) and $\mathrm{C}_{60}(\mathrm{OH})_{8}$ (a hydroxylated fullerene) on hIAPP aggregation remain unknown. In this study, we investigate the influences of pristine fullerene $\mathrm{C}_{60}$ and hydroxylated $\mathrm{C}_{60}$ on the dimerization of hIAPP using molecular dynamics (MD) simulations. Extensive replica exchange molecular dynamics (REMD) simulations show that isolated hIAPP dimers adopt $\beta$-sheet structure containing the amyloid-precursor ( $\beta$-hairpin). Both $\mathrm{C}_{60}$ and $\mathrm{C}_{60}(\mathrm{OH})_{8}$ notably inhibit the $\beta$-sheet formation of hIAPP dimer and induce the formation of collapsed disordered coil-rich conformations. Protein - nanoparticle interaction analyses reveal that the inhibition of hIAPP aggregation by $\mathrm{C}_{60}$ is mainly via hydrophobic and aromatic-stacking interactions, while the prevention of hIAPP aggregation by $\mathrm{C}_{60}(\mathrm{OH})_{8}$ is mostly through collective hydrogen bonding and aromatic-stacking interactions. Conventional MD simulations indicate that both $\mathrm{C}_{60}$ and $\mathrm{C}_{60}(\mathrm{OH})_{8}$ weaken the interactions within hIAPP protofibril and disrupt the $\beta$-sheet structure. These results provide mechanistic insights into the possible inhibitory mechanism of $\mathrm{C}_{60}$ and $\mathrm{C}_{60}(\mathrm{OH})_{8}$ toward hIAPP aggregation, and they are of great reference value for the screening of potent amyloid inhibitors.

Keywords: type 2 diabetes, hIAPP aggregation, inhibitory mechanism, replica exchange molecular dynamics simulations, $\mathrm{C}_{60}$

\section{INTRODUCTION}

Human islet amyloid polypeptide (hIAPP) is an intrinsically disordered protein and plays a significant role in the progression of type 2 diabetes (Cooper et al., 1987). hIAPP has a high propensity to form amyloid aggregates (Larson and Miranker, 2004; Brender et al., 2010). Amyloid deposits derived from hIAPP are observed in human islet extracellular space in type 2 diabetes and the formation of intracellular hIAPP oligomers may conduce to $\beta$-cell loss in Type 2 diabetes (Haataja et al., 2008). Inhibition of hIAPP aggregation and destabilization of preformed hIAPP fibrils are considered as two major therapeutic strategies for treating Type 2 diabetes. Finding an 
effective inhibitor of hIAPP aggregation is a crucial step for reducing islet $\beta$-cells death and the development of drugs against Type 2 diabetes. Researchers have made great efforts to search for inhibitors against hIAPP aggregation. Increasing experimental studies show that peptides (Yan et al., 2006; Abedini et al., 2007; Saunders et al., 2016), and natural small molecules (Cao and Raleigh, 2012; Palhano et al., 2013; Young et al., 2015; Pithadia et al., 2016) can modulate hIAPP aggregation and drive the peptides into disordered off-pathway aggregates which almost has no toxicity. Very recently, Ke et al. demonstrated that nanomaterials can inhibit hIAPP aggregation and reduce the toxicity in silico, in vitro, and in vivo (Wang et al., 2018; Faridi et al., 2019; Ke et al., 2019).

Carbon nanoparticles including graphene, carbon nanotube, fullerene, and its derivatives (especially hydroxylated fullerenes) have also been of great concern due to their excellent physicochemical properties (Mahmoudi et al., 2013) [such as high capacity to cross biological barriers (Tsuchiya et al., 1996; Sumner et al., 2010), low biotoxicity (Zhu et al., 2007), and high solubility (Da Ros and Prato, 1999; Maciel et al., 2011)]. Experimental studies have demonstrated that fullerenes and their derivatives can prevent the aggregation of amyloid proteins. For example, pristine fullerenes, carboxyfullerenes, and hydroxylated fullerene, strongly inhibit the aggregation of $A \beta$ and $A \beta$ fragments (Dugan et al., 1997; Kim and Lee, 2003; Podolski et al., 2007; Bobylev et al., 2011). Hydroxylated carbon nanotubes can significantly impede the aggregation of hIAPP (Mo et al., 2018). Graphene quantum dots are able to prevent the aggregation of hIAPP and reduce the toxicity in vivo (Wang et al., 2018). On the computational side, researchers investigated the interactions of amyloid proteins and carbon nanoparticles at atomic level of details with an attempt to uncover the underlying inhibitory mechanisms. By atomistic replica exchange molecular dynamics (REMD) simulations, Li et al. found that carbon nanotube can significantly suppress the formation of $\beta$ sheet rich $\mathrm{A} \beta_{16-22}$ oligomers ( $\mathrm{Li}$ et al., 2011). Using the same simulation method, Xie et al. explored the effect of different size of fullerenes on the aggregation of $A \beta_{16-22}$. Their simulations showed that fullerene $\mathrm{C}_{180}$, albeit with a smaller surface area than $3 \mathrm{C}_{60}$, exhibits an unexpectedly more effective inhibition of $\beta$ sheet formation. The stronger inhibition of $\beta$-sheet formation by $\mathrm{C}_{180}$ is due to the stronger hydrophobic and aromaticstacking interactions between the fullerene hexagonal rings and the Phe rings than that between the pentagonal rings and the Phe rings (Xie et al., 2014). MD simulations revealed that $C_{60}$ can destabilize $\mathrm{A} \beta$ protofibrils by disrupting the D23-K28 salt bridge (Andujar et al., 2012; Zhou et al., 2014). Guo et al. explored the influences of graphene, carbon nanotube, and $\mathrm{C}_{60}$ on oligomerization of IAPP $22-28$ fragment and found that these carbon nanoparticles inhibit the formation of the $\beta$-sheet-rich oligomers (Guo et al., 2013). However, questions remain to be addressed. For example, can pristine $\mathrm{C}_{60}$ inhibit the aggregation of full length hIAPP and disrupt hIAPP protofibrils? If yes, what is the inhibitory mechanism and how different is it from that of hydroxylated $\mathrm{C}_{60}$ ?

In this work, we conducted extensive explicit solvent replicaexchange molecular dynamics (REMD) simulations on hIAPP dimer with and without four $\mathrm{C}_{60} / \mathrm{C}_{60}(\mathrm{OH})_{8}$ nanoparticles. Our aim is to explore the effects of pristine and hydroxylated $\mathrm{C}_{60}$ nanoparticles on full-length hIAPP aggregation. REMD simulations showed that both $\mathrm{C}_{60}$ and $\mathrm{C}_{60}(\mathrm{OH})_{8}$ display a strong inhibition of $\beta$-sheet formation. The nanoparticle-peptide interactions analyses revealed that the strong $\beta$-sheet inhibition results from the strong binding of $\mathrm{C}_{60} / \mathrm{C}_{60}(\mathrm{OH})_{8}$ to hIAPP. $\mathrm{C}_{60}$ preferentially binds to the hydrophobic residues and aromatic residues, while $\mathrm{C}_{60}(\mathrm{OH})_{8}$ has a relatively high probability to bind to hydrophilic residues and aromatic residues. In addition, to examine whether $\mathrm{C}_{60} / \mathrm{C}_{60}(\mathrm{OH})_{8}$ nanoparticles can disrupt the preformed protofibril, we carried out conventional $\mathrm{MD}$ simulations for hIAPP protofibril in the absence and presence of $\mathrm{C}_{60} / \mathrm{C}_{60}(\mathrm{OH})_{8}$. The MD simulations revealed that both $\mathrm{C}_{60}$ and $\mathrm{C}_{60}(\mathrm{OH})_{8}$ can disrupt the $\beta$-sheet structure and destabilize hIAPP protofibril.

\section{MATERIALS AND METHODS}

\section{Systems}

\section{The hIAPP Dimer Systems}

The hIAPP dimer with/without $\mathrm{C}_{60} / \mathrm{C}_{60}(\mathrm{OH})_{8}$ nanoparticles, were simulated, and they were denoted as hIAPP-dimer, hIAPP-dimer $+\mathrm{C}_{60}$ and hIAPP-dimer $+\mathrm{C}_{60}(\mathrm{OH})_{8}$. hIAPP has 37 amino acid residues (with sequence KCNTATCATQ ${ }^{10}$ RLANFLVHSS ${ }^{20}$ NNFGAILSST $^{30}$ NVGSNTY) with an amidated C-terminus and a disulfide bond forming between Cys2 and Cys7. In accordance with previous experimental studies (Nanga et al., 2011), the N-terminus, the side chains of Lys1 and Arg11 were protonated $\left(\mathrm{NH}_{3}{ }^{+}, \mathrm{Lys}^{+}\right.$, and $\left.\mathrm{Arg}^{+}\right)$. And the sidechain of $\mathrm{H} 18$ was uncharged to mimic the experimental conditions with $\mathrm{pH}$ of $\sim 7.3$ (Goldsbury et al., 2000). It is true that the protonation state of His will change along with the local environment changes. As done recently by other groups (Dupuis et al., 2009, 2011; Deng et al., 2013; Qiao et al., 2013), we neglected the pKa shift in all of our simulations as the involvement of $\mathrm{pKa}$ calculation in $\mathrm{MD}$ simulations makes it very computationally expensive. Every hIAPP dimer was put in the center of a cubic box with a side length of $6.7 \mathrm{~nm}$. Four $\mathrm{C}_{60}$ or four $\mathrm{C}_{60}(\mathrm{OH})_{8}$ molecules were displaced in the solvated peptide system at random thus nanoparticle: peptide is 2:1 at molar ratio, which were consistent with previous simulation studies (Bai et al., 2019). The partial charges of oxygen and hydrogen atoms in hydroxyl groups were -0.8 and +0.3 , and that of carbon atoms bonded with hydroxyl groups in $\mathrm{C}_{60}(\mathrm{OH})_{8}$ was +0.5 , while other carbon atoms were uncharged (Goldsbury et al., 2000). Six counter ions $\left(\mathrm{Cl}^{-}\right)$were added to the three systems for neutralization. More details about the system preparation could be found in the Supporting Information section.

\section{The hIAPP Protofibril Systems}

The hIAPP protofibril with/without $\mathrm{C}_{60} / \mathrm{C}_{60}(\mathrm{OH})_{8}$ nanoparticles, are simulated, and they are denoted as hIAPPprotofibril, hIAPP-protofibril $+\mathrm{C}_{60}$ and hIAPP-protofibril + $\mathrm{C}_{60}(\mathrm{OH})_{8}$ systems. Kindly provided by Professor Tycko (Luca et al., 2007), the initial structure of hIAPP protofibril is a hIAPP decamer including two rotationally symmetric protofibrillar 
TABLE 1 | Secondary structure probabilities of hIAPP dimer in the absence or presence of carbon nanoparticles.

\begin{tabular}{|c|c|c|c|c|c|c|}
\hline \multirow[t]{2}{*}{ System } & \multicolumn{6}{|c|}{ Secondary structure content (\%) } \\
\hline & Coil & $\beta$-sheet & $\beta$-bridge & Bend & Turn & Helix \\
\hline hIAPP-dimer & $40.5 \pm 0.2$ & $10.6 \pm 0.4$ & $2.6 \pm 0.1$ & $27.3 \pm 0.4$ & $11.5 \pm 0.4$ & $7.5 \pm 0.1$ \\
\hline hlAPP-dimer + $\mathrm{C}_{60}$ & $46.7 \pm 0.2$ & $1.8 \pm 0.1$ & $3.3 \pm 0.4$ & $28.6 \pm 0.2$ & $12.5 \pm 0.05$ & $7.0 \pm 0.1$ \\
\hline hIAPP-dimer $+\mathrm{C}_{60}(\mathrm{OH})_{8}$ & $48.2 \pm 1.4$ & $4.2 \pm 0.1$ & $2.1 \pm 0.06$ & $29.7 \pm 0.8$ & $10.6 \pm 0.3$ & $5.2 \pm 0.1$ \\
\hline
\end{tabular}

pentamers, Each pentamer contains two anti-parallel $\beta$-strand, $\beta 1$ (spanning residues $8-17$ ) and $\beta 2$ (spanning residues $28-37$ ), and a "loop" (spanning residues 18-27). The three regions together formed a U-shaped structure. There are $20 \mathrm{C}_{60} / \mathrm{C}_{60}(\mathrm{OH})_{8}$ nanoparticles in hIAPP-protofibril $+\mathrm{C}_{60} / \mathrm{C}_{60}(\mathrm{OH})_{8}$ systems (nanoparticle: peptide $=2: 1$ in molar ratio). Thirty counter ions $\left(\mathrm{Cl}^{-}\right)$are added to the systems for neutralization. $\mathrm{C}_{60} / \mathrm{C}_{60}(\mathrm{OH})_{8}$ nanoparticles are randomly distributed in the simulation box. The dimensions of the simulation box are $9.5 \times 9.5 \times 9.5 \mathrm{~nm}^{3}$ for all the three systems.

\section{REMD and MD Simulations}

Both REMD and MD simulations are performed in the isothermal-isobaric (NPT) ensemble at a pressure of 1 bar using GROMACS-4.5.3 software package (Sugita and Okamoto, 1999; Nadler and Hansmann, 2008). We choose OPLS force field TIP4P water molecules, consistent with previous computational studies of hIAPP (Qi et al., 2014; Mo et al., 2016; Bai et al., 2019). hIAPP molecules are kept from the water box at least for $1.0 \mathrm{~nm}$. There are 48 replicas for each system in the REMD simulations, at different temperatures exponentially distributed from 306 to $409 \mathrm{~K}$. Every 1,000 integration steps, two adjacent replicas attempt to exchange with an average acceptance ratios of $\sim 15 \%$ for each system. The integration time step is $2 \mathrm{fs}$. Each replica was simulated for $360 \mathrm{~ns}$, and thus the accumulative simulation time period for each system was $17.28 \mu \mathrm{s}$. For MD simulations, we perform two individual 300 ns simulations for each of the three systems: hIAPP-protofibril and hIAPP-protofibril $+\mathrm{C}_{60}$ and hIAPP-protofibril $+\mathrm{C}_{60}(\mathrm{OH})_{8}$.

\section{Analysis Methods}

The tools implemented in GROMACS software package and our in-house developed codes were both used to analyze the trajectories. For REMD simulations, we chose the last $160 \mathrm{~ns}$ simulation data for analysis as the first 200 ns data of each replica may have bias of the initial structures. Daura method was used for cluster analysis with a $\mathrm{C}_{\alpha}$-root-mean-square deviation $\left(\mathrm{C}_{\alpha}\right.$-RMSD) cutoff of $0.35 \mathrm{~nm}$ (Daura et al., 1999). We analyzed the REMD trajectories by calculating the secondary structure propensities by the DSSP program, number of hydrogen bonds (H-bonds), percentage of $\beta$-strand length, free energy landscape (or potential of mean force), hIAPP-nanoparticles binding probabilities, and hIAPP-nanoparticles contact surface area (CSA), pairwise residue contact probabilities of both main chainmain chain (MC-MC) contact and side chain-side chain (SC-SC) contact. For MD simulations, H-bond number within hIAPP protofibril and between hIAPP and nanoparticles, secondary structure probabilities of hIAPP and the hIAPP-nanoparticle binding probability were calculated. The VMD (Humphrey et al., 1996) and Pymol (Schrodinger, 2015) programs were used for graphical structure analysis and trajectory visualization.

\section{RESULTS}

For each system at $310 \mathrm{~K}$, we examined the data convergence within two different time intervals (200-280 and 280-360 ns) before analyzing the REMD simulation data by comparing four parameters as followed. These parameters include the probability density functions (PDF) of the radius of gyration $(\mathrm{Rg})$ and the hydrogen bond (H-bond), the probabilities of coil, $\beta$-sheet and helix structure of each amino acid residue. As it can be seen in Figures S2-S5, the simulation data from the two independent time periods coincide very well in terms of all these parameters, demonstrating that the last 160 ns REMD simulations nicely converged. Unless specified, all the REMD simulation results presented below are based on the last $160 \mathrm{~ns}(t=200-360 \mathrm{~ns})$ simulation data generated at $310 \mathrm{~K}$.

\section{$\mathrm{C}_{60}$ and $\mathrm{C}_{60}(\mathrm{OH})_{8}$ Inhibit the Formation of $\beta$-sheet, Especially the Long $\beta$-sheet, of hIAPP Dimer}

We first examined the percentages of different types of secondary structure formed by hIAPP dimer in each REMD system and the results were listed in Table 1. For the isolated hIAPP dimer, the probabilities of coil and $\beta$-sheet are 40.5 and $10.6 \%$, respectively. The secondary structure propensities are in good agreement with previous circular dichroism (CD) studies (Kayed et al., 1999; Goldsbury et al., 2000) and with our recent REMD simulation results using AMBER99SB-ILDN force field (Lao et al., 2019). In comparison of the secondary structure content of isolated hIAPP dimer, the $\beta$-sheet contents of hIAPP dimer with $\mathrm{C}_{60}$ or $\mathrm{C}_{60}(\mathrm{OH})_{8}$ are reduced from $10.6 \%$ (hIAPP-dimer system) to $1.8 \%$ (hIAPP-dimer $+\mathrm{C}_{60}$ system) or $4.2 \%$ (hIAPP-dimer + $\mathrm{C}_{60}(\mathrm{OH})_{8}$ system) and the probability of coil increases from 40.5 to $46.7 \%$ or $48.2 \%$. The influences of $\mathrm{C}_{60} / \mathrm{C}_{60}(\mathrm{OH})_{8}$ on the probabilities of helix, turn, bend, and $\beta$-bridge structures are minor. The dominant secondary structure $(\beta$-sheet and coil) propensities of each residue of hIAPP dimer in the three systems are presented in Figures 1A,B. Figure 1A shows that residues in Q10-L16, S20-S29, and T30-T36 regions have the highest probabilities $(7.0-22.7 \%)$ to form $\beta$-sheets. The three regions are reported to be the amyloidogenic regions in many experimental studies (Jaikaran et al., 2001; Nielsen et al., 2009; 

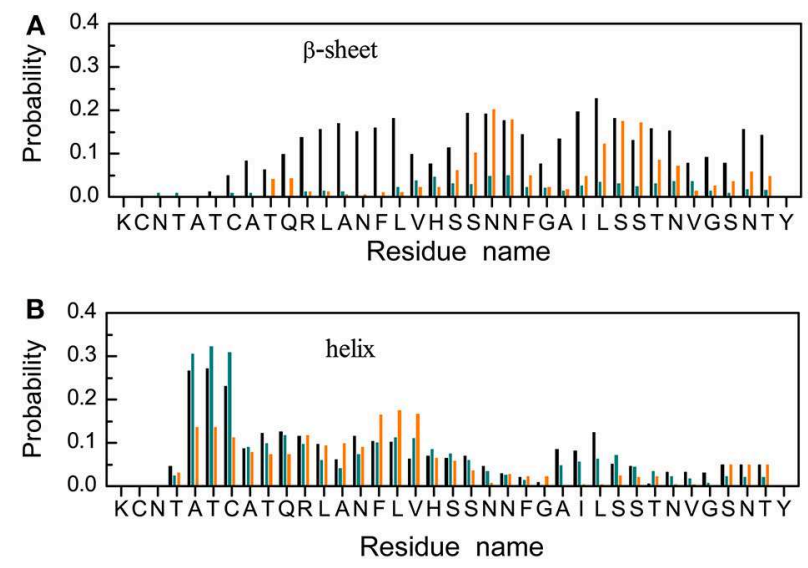

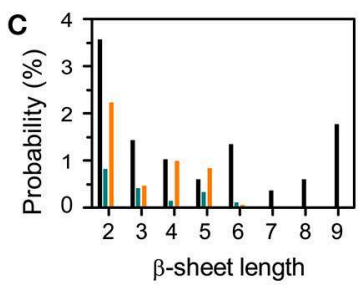

hIAPP-dimer

hIAPP-dimer $+\mathrm{C}_{60}$

$=$ hIAPP-dimer $+\mathrm{C}_{60}(\mathrm{OH})_{8}$

FIGURE 1 | Influence of $\mathrm{C}_{60}$ and $\mathrm{C}_{60}(\mathrm{OH})_{8}$ on the secondary structures of hIAPP dimer. Probabilities of $\beta$-sheet (A) and coil (B) as a function of amino acid residue. (C) The probability distribution of $\beta$-sheet length.

Bedrood et al., 2012; Zhang et al., 2013; Weirich et al., 2016). With the addition of $\mathrm{C}_{60}$, those $\beta$-sheet rich regions all display a reduced $\beta$-sheet probability (0.01-4.9\%) (the dark cyan bars in Figure 1A). In hIAPP-dimer $+\mathrm{C}_{60}(\mathrm{OH})_{8}$ system, except for polar residues N21, N22, S28, and S29, other residues including hydrophobic residues F23-L27 located in the primary amyloid core region (S20-S29) (Goldsbury et al., 2000; Brender et al., 2008; Dupuis et al., 2011) exhibit a dramatically decreased $\beta$-sheet probability (the orange bars in Figure 1A). The coil propensity of all these residues increases modestly in the presence of $\mathrm{C}_{60}$ or $\mathrm{C}_{60}(\mathrm{OH})_{8}$. As shown in Figure 1C, nanoparticles also affect the probability distribution of $\beta$-sheet length. Upon addition of $\mathrm{C}_{60}$ and $\mathrm{C}_{60}(\mathrm{OH})_{8}$, the probabilities of long $\beta$ sheets almost disappear. The probabilities of short $\beta$-sheets also decrease dramatically in the presence of $\mathrm{C}_{60}$, while their change becomes less prominent in hIAPP dimer $+\mathrm{C}_{60}(\mathrm{OH})_{8}$ system. Taken together, these data demonstrate that $\mathrm{C}_{60}$ and $\mathrm{C}_{60}(\mathrm{OH})_{8}$ substantially suppress hIAPP $\beta$-sheet formation, especially in the amyloidogenic core region, S20-S29.

\section{Both $\mathrm{C}_{60}$ and $\mathrm{C}_{60}(\mathrm{OH})_{8}$ Significantly Inhibit the Formation of $\beta$-hairpin Amyloid Precursor of hIAPP and Induce the Formation of Coil-Rich Conformations}

We first performed a RMSD-based cluster analysis for each REMD system at $310 \mathrm{~K}$ using a $\mathrm{C}_{\alpha}$-root-mean-square deviation $\left(\mathrm{C}_{\alpha}\right.$-RMSD) cutoff of $0.35 \mathrm{~nm}$ to investigate the three-dimensional (3D) conformations of hIAPP dimer in the three systems. The conformations of hIAPP dimer in the three systems were separated into 85, 73, and 68 clusters, respectively. Figure 2 showed the centers of the top six most populated clusters, which represent $42.5,44.0$, and $61.5 \%$ of all conformations, respectively, for the three systems. As shown in Figure 2A, hIAPP dimer transiently adopts a three-stranded antiparallel $\beta$-sheet structure with a $\beta$-hairpin, which was considered to be hIAPP amyloidogenic precursor (Dupuis et al., 2009, 2011; Qiao et al., 2013). In hIAPP dimer $+\mathrm{C}_{60}$ system, this $\beta$-hairpin structure disappears and both intra- and inter-chain $\beta$-sheet content dramatically reduced, leading to collapsed disordered coil-rich conformations (Figure 2B). In hIAPP dimer $+\mathrm{C}_{60}(\mathrm{OH})_{8}$ systems, inter-chain $\beta$-sheets are significantly reduced while a few intra-chain $\beta$-sheets (including short $\beta$-hairpins) still exist.

To have an overall view of the effects of $\mathrm{C}_{60}$ and $\mathrm{C}_{60}(\mathrm{OH})_{8}$ on the whole space of conformations of hIAPP dimer, we plotted the two-dimensional (2D) free energy landscape as a function of H-bond number and $\mathrm{Rg}$. It can be seen from Figure 2D that there are three minimum-energy basins of the free energy surface of isolated hIAPP dimer, located at (H-bond number, $\mathrm{Rg}$ ) values of $(40.0,1.52 \mathrm{~nm}),(40.0,1.23 \mathrm{~nm})$, and $(38.0,1.14 \mathrm{~nm})$. The first basin with the largest $\mathrm{Rg}$ values corresponds to the three-stranded antiparallel $\beta$-sheet structure with a $\beta$-hairpin as mentioned earlier. In the presence of $\mathrm{C}_{60}$ (Figure 2E), hIAPP dimer has only one narrow and deep basin located at $(30.0,1.28 \mathrm{~nm})$, corresponding to collapsed disordered dimers. It is noteworthy that the basin located at $(40.0,1.52 \mathrm{~nm})$ disappears, indicating that the $\beta$-hairpin amyloid precursor of hIAPP is completely suppresses in presence of $\mathrm{C}_{60}$. With $\mathrm{C}_{60}(\mathrm{OH})_{8}$ (Figure 2F), the free energy landscape becomes shallower than that of the isolated hIAPP dimer and has a basin centered at $(28.0,1.35 \mathrm{~nm})$. The decreased number of $\mathrm{H}$-bond and the increased range of $\mathrm{Rg}$ imply a collapsed and loosely packed coil-rich hIAPP dimer.

\section{Both $\mathrm{C}_{60}$ and $\mathrm{C}_{60}(\mathrm{OH})_{8}$ Weaken the Inter- and Intra-peptide Interactions of hIAPP Dimer}

To explore the effects of $\mathrm{C}_{60}$ and $\mathrm{C}_{60}(\mathrm{OH})_{8}$ on the hIAPP interactions, we plotted the pairwise residue inter-peptide and intra-peptide MC-MC (Figures 3A-C) and SC-SC (Figure S6) contact probabilities of hIAPP dimer in the three systems. The maps of contact probability in these three systems display distinct interaction patterns, suggesting that both interpeptide and intra-peptide interactions are remarkably altered by $\mathrm{C}_{60}$ and $\mathrm{C}_{60}(\mathrm{OH})_{8}$. As shown in Figure $\mathbf{3 A}$, without 


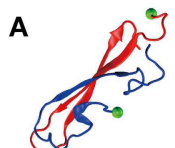

C1 $10.9 \%$

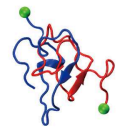

C2 $8.8 \%$

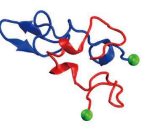

C3 $7.3 \%$

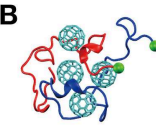

C1 $10.8 \%$

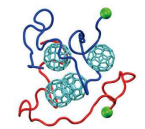

C2 $8.2 \%$

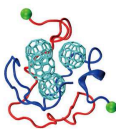

C3 $7.7 \%$

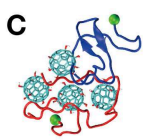

C1 15.6\%

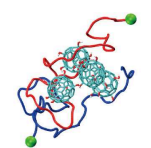

C2 12\%

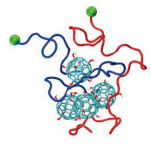

C3 $10.5 \%$

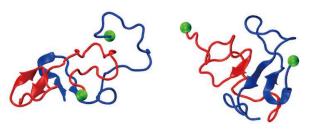

C4 5.9\%

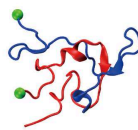

C6 4.6\%

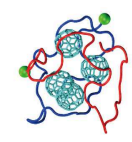

C4 6.8\%

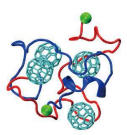

C5 5.8\%

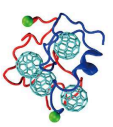

C6 4.7\%

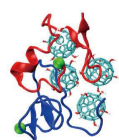

C4 10.1\%

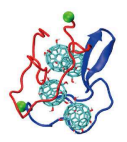

C5 7.6\%

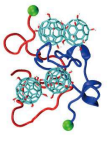

C6 5.7\%
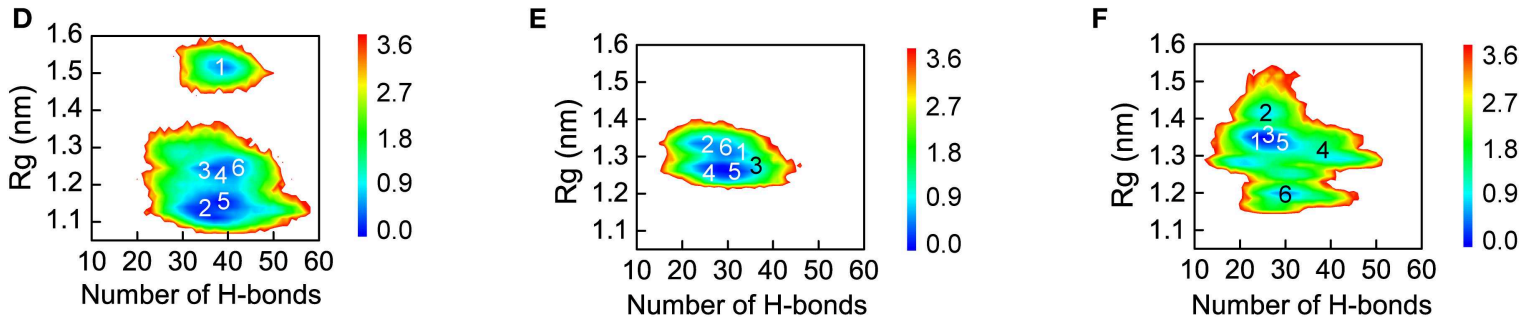

FIGURE 2 | Analysis of 3D conformational properties and 2D free energy landscape of hIAPP dimer with and without $\mathrm{C}_{60} / \mathrm{C}_{60}\left(\mathrm{OH}_{8}\right.$. Representative conformations of the first six most-populated clusters for hIAPP dimer in hIAPP-dimer (A), hIAPP-dimer $+\mathrm{C}_{60} \mathbf{( B )}$, and hIAPP-dimer $+\mathrm{C}_{60}(\mathrm{OH})_{8} \mathbf{( C )}$ systems. The corresponding population of each cluster is given below the snapshots. Free energy landscape (in $\mathrm{kcal} / \mathrm{mol}$ ) of hlAPP dimer as a function of the total number of $\mathrm{H}$-bonds and Rg for three systems (D-F). The numbers in the PMF correspond to the cluster index. The green balls refer to the $\mathrm{C}_{\alpha}$ atoms of the $\mathrm{N}$-terminal residue $\mathrm{K} 1$.

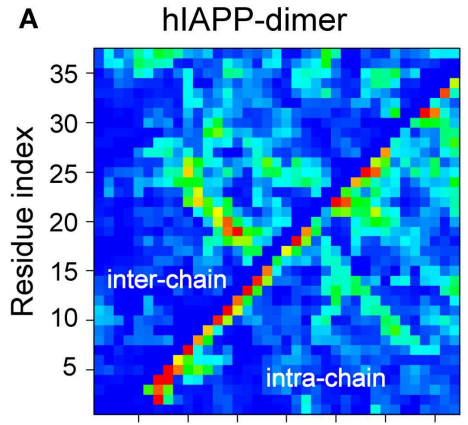

$\begin{array}{lllllll}5 & 10 & 15 & 20 & 25 & 30 & 35\end{array}$

Residue index

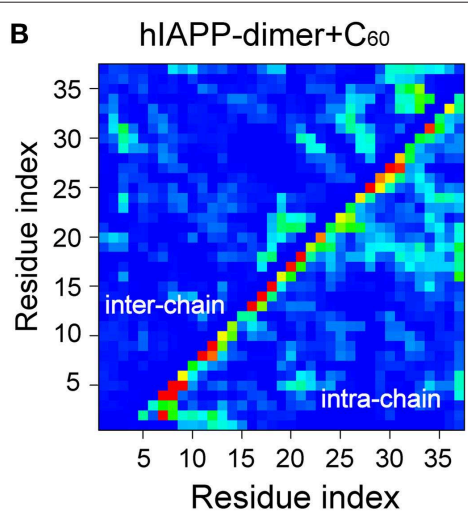

hIAPP-dimer+C60

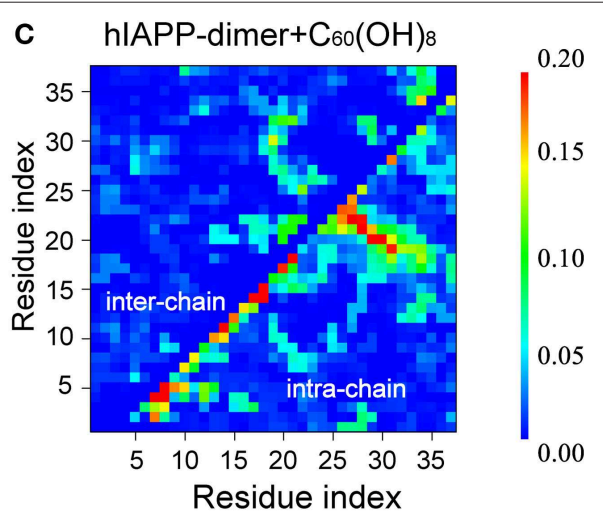

hIAPP-dimer+ $\mathrm{C}_{60}(\mathrm{OH}) 8$
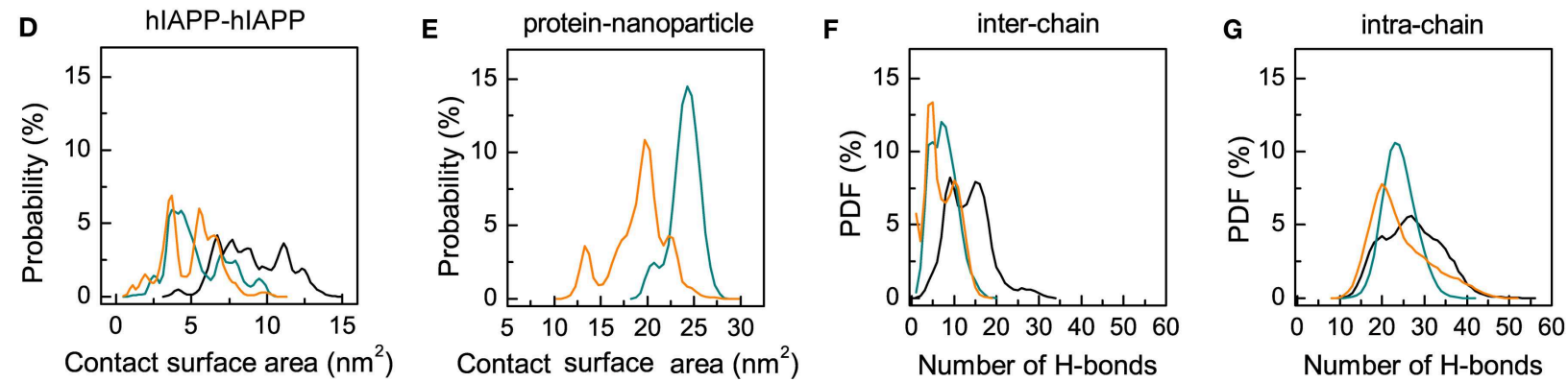

FIGURE 3 | Analysis of the effects of $\mathrm{C}_{60} / \mathrm{C}_{60}(\mathrm{OH})_{8}$ on the hIAPP interactions. Inter- and intra-peptide MC-MC contact probability maps for hIAPP dimer in the three different systems, hIAPP-dimer (A), hIAPP-dimer $+\mathrm{C}_{60} \mathbf{( B )}$, and hIAPP-dimer $+\mathrm{C}_{60}(\mathrm{OH})_{8} \mathbf{( C )}$. PDF of protein-protein (D) and protein-nanoparticle (E) contact surface area (CSA). PDF of inter-chain (F) and intra-chain (G) $\mathrm{H}$-bond number. 
nanoparticles, residues $\mathrm{V} 17-\mathrm{L} 27$ and $\mathrm{C} 7-\mathrm{V} 17$ present the dominant probabilities of inter-chain contact. The highest probabilities of intra-chain $\mathrm{MC}-\mathrm{MC}$ contact show strong antidiagonal contacts between A8-L16 and A25-G33, suggesting the appearance of the amyloid precursor $\beta$-hairpin structure that many studies previously reported (Jiang et al., 2009; Xu et al., 2009; Qi et al., 2014; Zhao et al., 2015; Qiao et al., 2016). In the presence of $C_{60}$, the $\beta$-hairpin pattern disappears and both the inter- and intra-chain contact probabilities are observably reduced (Figure 3B). With $\mathrm{C}_{60}(\mathrm{OH})_{8}$ molecules, the inter-chain contact probabilities greatly decrease, and the amyloid precursor $\beta$-hairpin structure pattern disappears. Other short $\beta$-hairpin structures, such as that formed between S28N31 and S19-N22, were also observed (Figure 3C). The results above demonstrate that $\mathrm{C}_{60}$ can markedly block both intra- and inter-peptide interactions critical for hIAPP aggregation, while $\mathrm{C}_{60}(\mathrm{OH})_{8}$ dramatically alters intra-peptide interaction patterns and weakens inter-peptide interactions.

We also analyzed the contact surface area (CSA) probability between the two hIAPP monomers. without nanoparticles, the average inter-chain CSA value is $9.0 \mathrm{~nm}^{2}$. In the presence of $\mathrm{C}_{60} / \mathrm{C}_{60}(\mathrm{OH})_{8}$ (Figure 3D), the average inter-chain CSA reduces to 5.3/4.9 $\mathrm{nm}^{2}$ while the CSA between hIAPP and nanoparticles is large (Figure 3E), indicating a strong binding between nanoparticles and hIAPP. We also find that hIAPP has a larger contact surface area with $\mathrm{C}_{60}$ than $\mathrm{C}_{60}(\mathrm{OH})_{8}$, resulting in a more prominent inhibitory effect of $\mathrm{C}_{60}$. We further calculated the probability density function (PDF) of H-bond number formed within hIAPP dimer in the three systems. As shown in Figures 3F,G, in the presence of $\mathrm{C}_{60}$ or $\mathrm{C}_{60}(\mathrm{OH})_{8}$, the numbers of inter-chain $\mathrm{H}$-bonds are dramatically decreased as a result of the interactions between hIAPP and nanoparticles. These data suggest that the hIAPP- $\mathrm{C}_{60} / \mathrm{C}_{60}(\mathrm{OH})_{8}$ interaction is stronger than hIAPP-hIAPP interaction, thus weaken hIAPPhIAPP interactions and prevent hIAPP aggregation. Our result is consistent with recent studies showing that whether nanoparticles can inhibit or prevent peptide aggregation depends on the competition between peptide-peptide and peptidenanoparticle interactions (Gladytz et al., 2016; Ke et al., 2019).

\section{$\mathrm{C}_{60}$ Preferentially Binds to Hydrophobic and Aromatic Residues, While $\mathrm{C}_{60}(\mathrm{OH})_{8}$ Has a Relatively High Probability to Bind to Hydrophilic and Aromatic Residues}

To identify the most favorable binding sites of nanoparticles, we calculated the contact probabilities of $\mathrm{C}_{60} / \mathrm{C}_{60}(\mathrm{OH})_{8}$ with each amino acid residue of hIAPP. Figures $4 \mathrm{~A}, \mathrm{~B}$ shows that $\mathrm{C}_{60}$ nanoparticles have a relatively high probability to bind with the hydrophobic residues L12, L16, V17, L27, V32, and aromatic residues F15, F23, and Y37, reflecting that both hydrophobic and aromatic interactions play an important role in inhibiting hIAPP dimerization. It is well-known that $\pi-\pi$ stacking of aromatic residues is crucial to the amyloid fibril formation (Azriel and Gazit, 2001; Gazit, 2002; Porat et al., 2004). It can be seen from Figures 4A,B that $\mathrm{C}_{60}$ and $\mathrm{C}_{60}(\mathrm{OH})_{8}$ both have high propensities to interact with F15, F23, and Y37, which

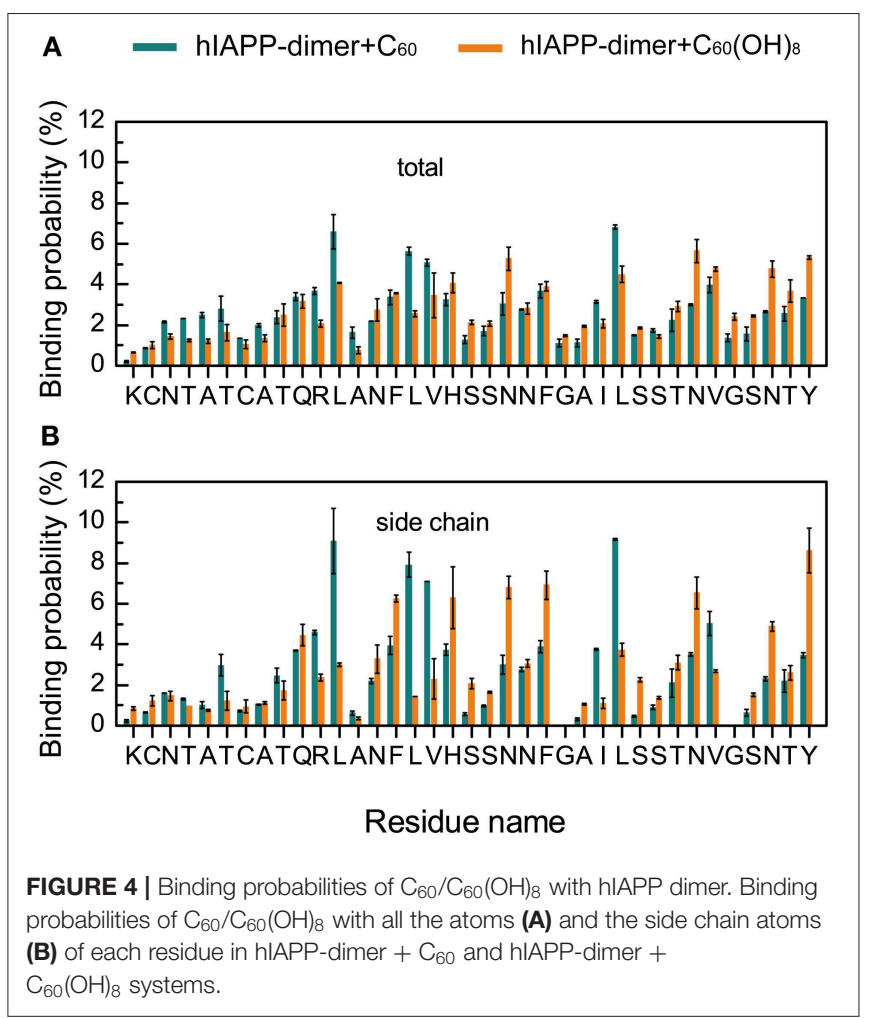

are the only three aromatic residues and proposed to be of great importance in hIAPP aggregation (Padrick and Miranker, 2001; Marek et al., 2007). We also find that $\mathrm{C}_{60}(\mathrm{OH})_{8}$ has a relatively high probability to bind with hydrophilic residues $\mathrm{H} 18$, N21, N31, and N35. The hydroxylation of $\mathrm{C}_{60}$ makes it more hydrophilic than pristine $\mathrm{C}_{60}$, which weakens its interactions with hydrophobic amino acids and enhances its interactions with hydrophilic amino acids. Therefore, $\mathrm{C}_{60}$ and $\mathrm{C}_{60}(\mathrm{OH})_{8}$ display different binding sites on hIAPP.

Interestingly, we find that, the positively charged residues R11 in hIAPP dimer have relatively high binding probabilities with the hydrophobic $\mathrm{C}_{60}$. Thus, we calculated the minimum distance distribution between the atom NE of the side chain of $\mathrm{R} 11$ and the geometry center of each ring of $\mathrm{C}_{60}$. The distance distribution curve in Figure 5A shows that there exists a sharp peak centered at $0.40 \mathrm{~nm}$, indicating strong cation- $\pi$ interactions between R11 and $\mathrm{C}_{60}$ (Figure 5B). We can see from Figure 4 that $\mathrm{C}_{60}$ has a high contact probability with hydrophobic residue L12, this strong hydrophobic interaction might induce the cation- $\pi$ interaction between $\mathrm{R} 11$ and $\mathrm{C}_{60}$.

Another interesting phenomenon is that $\mathrm{C}_{60}$ has stronger hydrophobicity than $\mathrm{C}_{60}(\mathrm{OH})_{8}$, but $\mathrm{C}_{60}(\mathrm{OH})_{8}$ exhibits much higher binding probability with the side chains of aromatic residues F15, H18, F23, and Y37 than $\mathrm{C}_{60}$ (Figure 4B). Meanwhile we noticed that $\mathrm{C}_{60}(\mathrm{OH})_{8}$ displays high interacting probabilities with their neighboring residues N14, N21, and N35. To understand this observation at atomic level, we computed the minimum distance distribution between N14/N21/N35 and $\mathrm{C}_{60} / \mathrm{C}_{60}(\mathrm{OH})_{8}$. The distance distribution curve in Figure 5C 


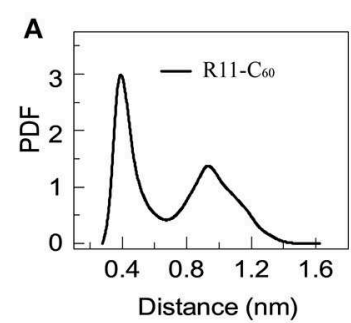

B

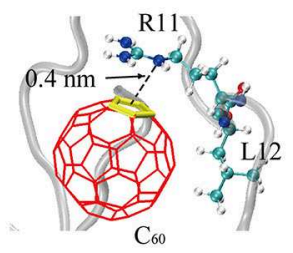

C

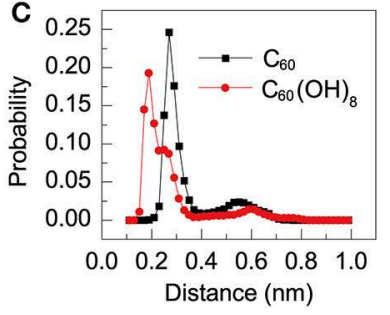

D

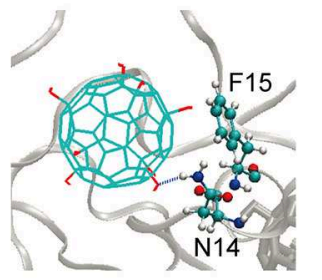

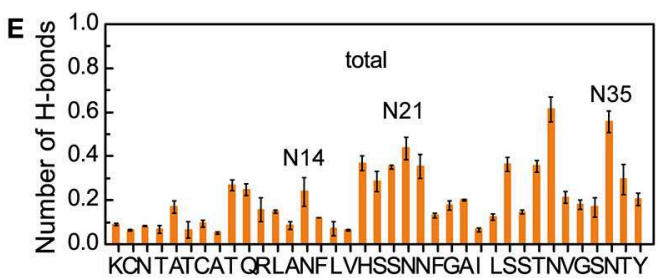

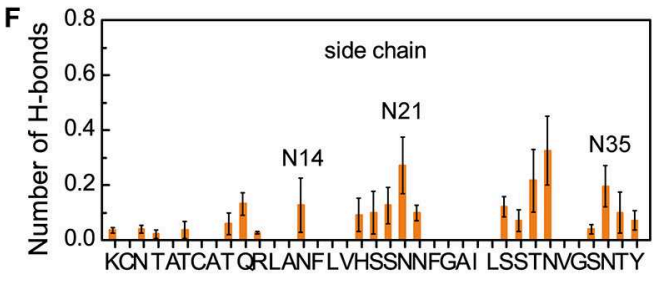

Residue name

FIGURE 5 | Binding mechanism of $\mathrm{C}_{60} / \mathrm{C}_{60}(\mathrm{OH})_{8}$ on hIAPP dimer. (A) PDF of the minimum distance between NE atom of R11 and the geometry center of the $\mathrm{C}_{60}$ ring; (B) a representative snapshot showing the cation- $\pi$ interaction between the atom $\mathrm{NE}$ in residue $\mathrm{R} 11$ and the ring of $\mathrm{C}_{60}$; (C) probability distribution of the minimum distance between $\mathrm{N} 14 / \mathrm{N} 21 / \mathrm{N} 35$ and $\mathrm{C}_{60} / \mathrm{C}_{60}(\mathrm{OH})_{8}$. (D) A representative snapshot showing the collective hydrophilic and aromatic-stacking interactions between $\mathrm{C}_{60}(\mathrm{OH})_{8}$ and hIAPP. (E) Total number of $\mathrm{H}$-bonds between $\mathrm{C}_{60}(\mathrm{OH})_{8}$ and each residue of hIAPP. (F) Number of $\mathrm{H}_{-}$-bonds between $\mathrm{C}_{60}(\mathrm{OH})_{8}$ and the side chain of each hIAPP residue.

shows that the distance between $\mathrm{C}_{60}(\mathrm{OH})_{8}$ and residue N14/N21/N35 is much shorter than that between $\mathrm{C}_{60}$ and $\mathrm{N} 14 / \mathrm{N} 21 / \mathrm{N} 35$. This result is probably attributed to the $\mathrm{H}$ bond formation between the hydroxyl group of $\mathrm{C}_{60}(\mathrm{OH})_{8}$ and Asn. Thus, we calculated the H-bond number between $\mathrm{C}_{60}(\mathrm{OH})_{8}$ and each residue of hIAPP and found that residues $\mathrm{N} 14, \mathrm{~N} 21$, and $\mathrm{N} 35$ all have high propensities to form $\mathrm{H}$ bonds with $\mathrm{C}_{60}(\mathrm{OH})_{8}$ (Figures 5E,F). These results suggest that the relatively high binding probability of $\mathrm{C} 60(\mathrm{OH})_{8}$ with the aromatic residues F15, F23, and Y37 results from the cooperative contribution of aromatic interactions between F15, F23, Y37, and $\mathrm{C}_{60}(\mathrm{OH})_{8}$, and hydrogen bonding interactions between their nearest neighboring residues $\mathrm{N} 14, \mathrm{~N} 21, \mathrm{~N} 35$, and $\mathrm{C}_{60}(\mathrm{OH})_{8}$ (Figure 5D). We also find four consecutive hydrophilic residues S19, S20 N21, and N22 in the amyloid core region and four consecutive hydrophilic residues S28, S29, T30, and N31 in the $\mathrm{C}$-terminal region that have high propensities to form $\mathrm{H}$-bonds with $\mathrm{C}_{60}(\mathrm{OH})_{8}$. It indicates that hydrogen bonding interaction between $\mathrm{C}_{60}(\mathrm{OH})_{8}$ and hydrophilic residues of hIAPP also plays a role in inhibiting hIAPP aggregation.

\section{Both $\mathrm{C}_{60}$ and $\mathrm{C}_{60}(\mathrm{OH})_{8}$ Weaken the Protein-Protein Interactions and Disrupt the hIAPP Protofibril}

We further performed MD simulations to probe into the effects of $\mathrm{C}_{60} / \mathrm{C}_{60}(\mathrm{OH})_{8}$ on preformed hIAPP protofibrils. As shown in Figures 6A,B, compared to the $\beta$-sheet content in hIAPPprotofibril system $(44.66 \%), \beta$-sheet probabilities are reduced in both the hIAPP-protofibril $+\mathrm{C}_{60}(38.67 \%)$ and hIAPPprotofibril $+\mathrm{C}_{60}(\mathrm{OH})_{8}(39.16 \%)$ systems, especially for the $\mathrm{N}$ - and $\mathrm{C}$-terminal residues of the $\beta$-sheet regions ( $\beta 1$ and $\beta 2$ ). It should be pointed out that the $\beta$-sheet disruption by
$\mathrm{C}_{60} / \mathrm{C}_{60}(\mathrm{OH})_{8}$ is less pronounced than $\beta$-sheet inhibition $(\beta$ sheet probability: $10.6 \%$ in hIAPP-dimer system, $1.8 \%$ in hIAPPdimer $+\mathrm{C}_{60}$ system and $4.2 \%$ in hIAPP-dimer $+\mathrm{C}_{60}(\mathrm{OH})_{8}$ system). The snapshots in Figure $\mathbf{6 C}$ shows that all the $\mathrm{C}_{60}$ and $\mathrm{C}_{60}(\mathrm{OH})_{8}$ molecules bind to the surface of hIAPP protofibril. It can be seen in Figure $6 \mathrm{~F}$ that the favorite binding sites of $\mathrm{C}_{60}$ and $\mathrm{C}_{60}(\mathrm{OH})_{8}$ are the three aromatic amino acids, F15, F23, and Y37, revealing that the $\pi-\pi$ staking may play a crucial role in the protein-nanoparticles interactions. F15 and F23 are located, respectively, in the C-terminal region of the $\beta 1$ and the turn region of the protofibril, and Y37 is near the turn region in space. In addition, other residues with high binding probabilities are mostly located in the regions of the turn and the C-terminal of $\beta 1$. These results demonstrate that both $\mathrm{C}_{60}$ and $\mathrm{C}_{60}(\mathrm{OH})_{8}$ prefer to bind to the turn and the $\mathrm{C}$-terminal of $\beta 1$. The strong protein $-\mathrm{C}_{60} / \mathrm{C}_{60}(\mathrm{OH})_{8}$ interactions significantly weaken and remodel the protein-protein interactions (Figures 6D,E, Figures S7A-F, S8). It is noted that $\mathrm{C}_{60}(\mathrm{OH})_{8}$ displays a less prominent protofibril disruptive effect than $\mathrm{C}_{60}$, indicating the H-bonds (Figure 6G) formed between hydroxyl groups of $\mathrm{C}_{60}(\mathrm{OH})_{8}$ and hIAPP might have limited disruptive effects on the protein-protein interactions. Taken together, both $\mathrm{C}_{60}$ and $\mathrm{C}_{60}(\mathrm{OH})_{8}$ weaken the protein-protein interactions and disrupt the secondary structures.

\section{DISCUSSION}

In this study, we performed both REMD and MD simulations to study the effects of pristine and hydroxylated $\mathrm{C}_{60}$ on hIAPP aggregation. All-atom REMD simulations of hIAPP dimers reveal that $\mathrm{C}_{60}$ and $\mathrm{C}_{60}(\mathrm{OH})_{8}$ can significantly suppress $\beta$-sheet formation of hIAPP. We found that, isolated hIAPP dimers adopt mostly disordered coil with a small proportion of short $\beta$-sheets. 


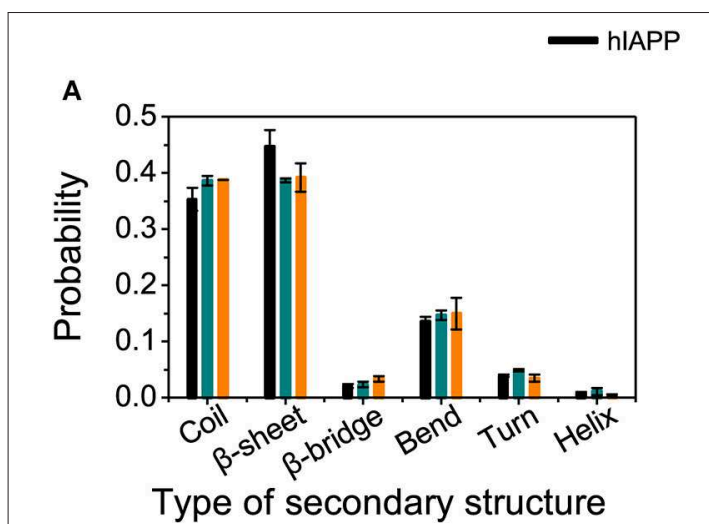

C

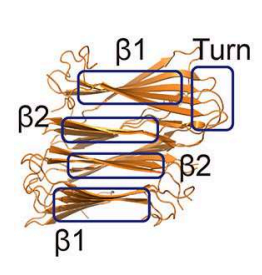

hIAPP $t=300 n s$

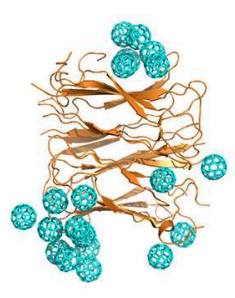

hIAPP+C 60

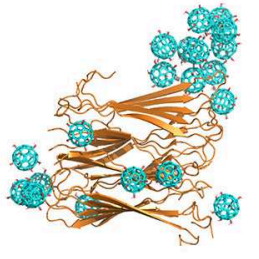

$\mathrm{hIAPP}+\mathrm{C}_{60}(\mathrm{OH})_{8}$
B

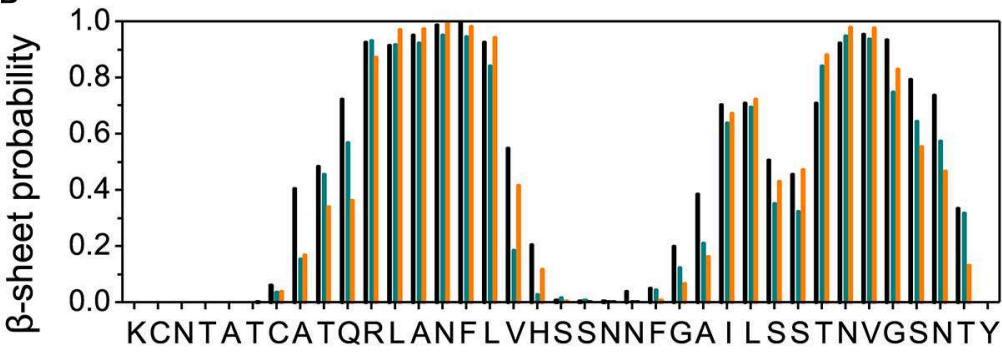

Residue name
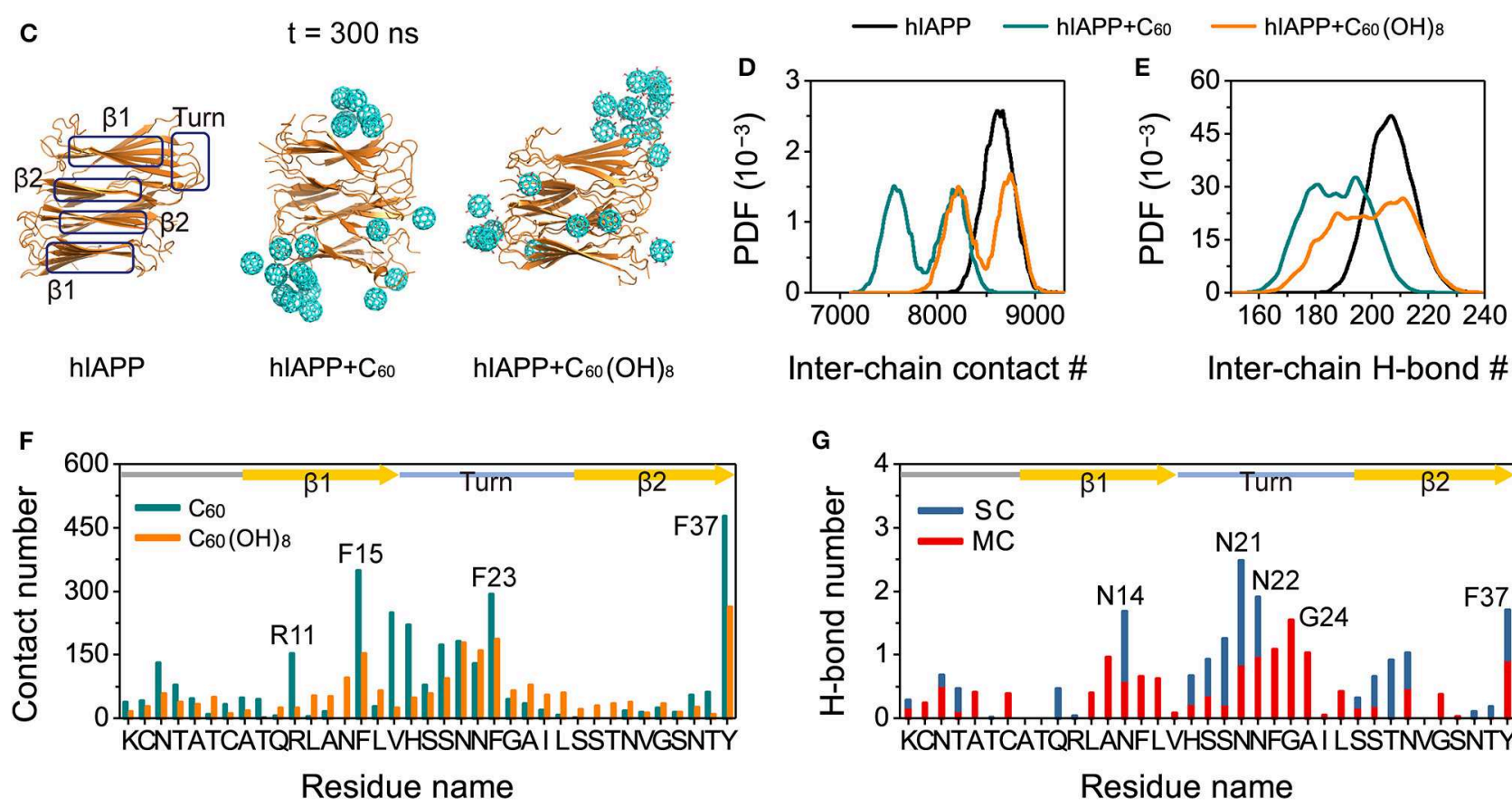

Inter-chain contact \#

Inter-chain $\mathrm{H}$-bond \#

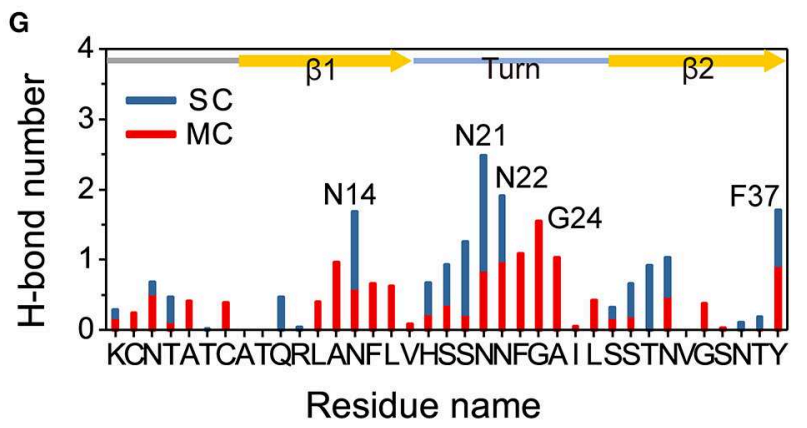

FIGURE 6 | Influences of $\mathrm{C}_{60}$ and $\mathrm{C}_{60}(\mathrm{OH})_{8}$ on the hIAPP protofibril. The average probability of each type of secondary structure (A), the $\beta$-sheet probability of each amino acid of hIAPP (B), the snapshots of hIAPP protofibril at $t=300 \mathrm{~ns}(\mathbf{C})$, the PDF of the inter-chain contact number (abbreviated as \#) (D) and the inter-chain $\mathrm{H}$-bond number (E) for hIAPP-fibril, hIAPP-fibril $+\mathrm{C}_{60}$, and hIAPP-fibril $+\mathrm{C}_{60}(\mathrm{OH})_{8}$ systems, contact number between $\mathrm{C}_{60} / \mathrm{C}_{60}(\mathrm{OH})_{8}$ and each amino acid of hIAPP (F), the number of $\mathrm{H}$-bond formed between $\mathrm{C}_{60}(\mathrm{OH})_{8}$ and the main-chain $(\mathrm{MC})$ and side-chain $(\mathrm{SC})$ atoms of each amino acid $(\mathbf{G})$. The $\beta 1, \beta 2$, and turn regions are

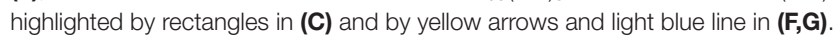

Interestingly, the previously proposed $\beta$-hairpin amyloidogenic precursor (Dupuis et al., 2009), contained in a three-stranded antiparallel $\beta$-sheet structure is also transiently populated. In the presence of $\mathrm{C}_{60}$ or $\mathrm{C}_{60}(\mathrm{OH})_{8}$, the three-stranded antiparallel $\beta$ sheet structure with a $\beta$-hairpin completely disappears, resulting in disordered coil states. Protein-nanoparticle and proteinprotein interaction analysis shows that $\mathrm{C}_{60}$ and $\mathrm{C}_{60}(\mathrm{OH})_{8}$ both have strong binding with hIAPP and disrupt the peptidepeptide interactions responsible for hIAPP aggregation. These results indicate that both $\mathrm{C}_{60}$ and $\mathrm{C}_{60}(\mathrm{OH})_{8}$ could slow down or hinder the aggregation of hIAPP. Further analyses reveal that the inhibition of hIAPP aggregation by $\mathrm{C}_{60}$ and
$\mathrm{C}_{60}(\mathrm{OH})_{8}$ is through different mechanism: hydrophobic and aromatic-stacking interactions for $\mathrm{C}_{60}$, and collective hydrogen bonding and aromatic-stacking interactions for $\mathrm{C}_{60}(\mathrm{OH})_{8}$. MD simulations indicate that both $\mathrm{C}_{60}$ and $\mathrm{C}_{60}(\mathrm{OH})_{8}$ are more likely to bind to the turn and the $\mathrm{C}$-terminal of $\beta 1$ via hydrophobic interactions, weaken the protein-protein interactions and disrupt the $\beta$-sheet of hIAPP protofibril. The obtained results are helpful for understanding the possible inhibitory mechanism of $\mathrm{C}_{60}$ and $\mathrm{C}_{60}(\mathrm{OH})_{8}$ on hIAPP aggregation and provided valuable reference for the screening of potent amyloid inhibitors.

The $\beta$-sheet inhibition effect of $\mathrm{C}_{60} / \mathrm{C}_{60}(\mathrm{OH})_{8}$ on amyloid proteins is sequence dependent. For example, this study together 
with our previous work shows that $\mathrm{C}_{60}$ can observably inhibit the $\beta$-sheet formation of $A \beta_{16-22}$ (Xie et al., 2014) and hIAPP, while a recent $M D$ study by Sun et al. reported that pristine $C_{60}$ displays weak inhibitory impact on the aggregation of NACore of $\alpha$-synuclein (Sun et al., 2019). Similarly, our REMD study demonstrates that $\mathrm{C}_{60}$ exhibits stronger inhibition capacity on hIAPP aggregation than $\mathrm{C}_{60}(\mathrm{OH})_{8}$, whereas the work by Sun et al. shows that $\mathrm{C}_{60}$ has weaker inhibition ability on the aggregation of NACore of $\alpha$-synuclein than $\mathrm{C}_{60}(\mathrm{OH})_{8}$. It is noted that $\mathrm{C}_{60}$ and $\mathrm{C}_{60}(\mathrm{OH})_{8}$ have poor water solubility, which limits their applications. This limitation can be overcome by increasing their extent of hydroxylation or their hydrophilicity through chemical modifications. Recently, it has been reported that graphene quantum dots and gold nanoparticles display excellent inhibition capacity against amyloidosis of hIAPP (Kim et al., 2018; Javed et al., 2019). Our results together with previous studies (Cabaleiro-Lago et al., 2012; Xie et al., 2014; Bednarikova et al., 2016; Nedumpully-Govindan et al., 2016; Kim et al., 2018) provide a better understanding of the inhibitory mechanism of nanomaterials targeting protein aggregation.

\section{DATA AVAILABILITY STATEMENT}

The datasets generated for this study are available on request to the corresponding author.

\section{AUTHOR CONTRIBUTIONS}

$\mathrm{CB}$ and GW conceived and designed the research. $\mathrm{CB}$ performed the simulations. $\mathrm{CB}, \mathrm{ZL}, \mathrm{YC}$, and YT analyzed the simulation data. $\mathrm{CB}$ and GW wrote the paper and all authors approved the article.

\section{REFERENCES}

Abedini, A., Meng, F., and Raleigh, D. P. (2007). A single-point mutation converts the highly amyloidogenic human islet amyloid polypeptide into a potent fibrillization inhibitor. J. Am. Chem. Soc. 129, 11300-11301. doi: $10.1021 / j a 072157 y$

Andujar, S. A., Lugli, F., Höfinger, S., Enriz, R. D., and Zerbetto, F. (2012). Amyloid-beta fibril disruption by $\mathrm{C} 60$-molecular guidance for rational drug design. Phys. Chem. Chem. Phys. 14, 8599-8607. doi: 10.1039/c2cp40680b

Azriel, R., and Gazit, E. (2001). Analysis of the minimal amyloid-forming fragment of the islet amyloid polypeptide. an experimental support for the key role of the phenylalanine residue in amyloid formation. J. Biol. Chem. 276, 34156-34161. doi: 10.1074/jbc.M102883200

Bai, C., Lin, D., Mo, Y., Lei, J., Sun, Y., Xie, L., et al. (2019). Influence of fullerenol on hIAPP aggregation: amyloid inhibition and mechanistic aspects. Phys. Chem. Chem. Phys. 21, 4022-4031. doi: 10.1039/C8CP07501H

Bednarikova, Z., Huy, P. D. Q., Mocanu, M. M., Fedunova, D., Li, M. S., and Gazova, Z. (2016). Fullerenol C-60(OH)(16) prevents amyloid fibrillization of a beta(40)-in vitro and in silico approach. Phys. Chem. Chem. Phys. 18, 18855-18867. doi: 10.1039/C6CP00901H

Bedrood, S., Li, Y., Isas, J. M., Hegde, B. G., Baxa, U., Haworth, I. S., et al. (2012). Fibril structure of human islet amyloid polypeptide. J. Biol. Chem. 287, 5235-5241. doi: 10.1074/jbc.M111.327817

Bobylev, A. G., Kornev, A. B., Bobyleva, L. G., Shpagina, M. D., Fadeeva, I. S., Fadeev, R. S., et al. (2011). Fullerenolates: metallated polyhydroxylated

\section{FUNDING}

This work was supported by the NSF of China (Grant No. 11674065) and National Key Research and Development Program of China (Grant No. 2016YFA0501702).

\section{ACKNOWLEDGMENTS}

All simulations were performed using the high-performance computational facilities at the National High Performance Computing Center of Fudan University and at Guangzhou Supercomputer Center.

\section{SUPPLEMENTARY MATERIAL}

The Supplementary Material for this article can be found online at: https://www.frontiersin.org/articles/10.3389/fchem. 2020.00051/full\#supplementary-material

Additional data are provided, including construction of initial structures of hIAPP dimer, parameters for simulation data analyses, temperature list, and eight supplementary figures. These figures present the initial states of the hIAPP dimer in our REMD simulations, the convergence check for the REMD runs of the three systems, inter-/intra-chain SC-SC contact probability maps, inter-chain contact number, interchain $\mathrm{H}$-bond number, and the differentials of the interchain contact maps. In the figures of the convergence check, several parameters were used, including $\mathrm{H}$-bonds number, $\mathrm{Rg}$, the average probability of each types of secondary structure, secondary structure propensity of each residue at $310 \mathrm{~K}$. We use two time periods, $200-280$ and $280-360$ ns for analysis in all the REMD systems.

fullerenes with potent anti-amyloid activity. Org. Biomol. Chem. 9, 5714-5719. doi: $10.1039 / \mathrm{cl}$ ob05067b

Brender, J. R., Hartman, K., Nanga, R. P., Popovych, N., de la Salud Bea, R., Vivekanandan, S., et al. (2010). Role of zinc in human islet amyloid polypeptide aggregation. J. Am. Chem. Soc. 132, 8973-8983. doi: 10.1021/ja1007867

Brender, J. R., Lee, E. L., Cavitt, M. A., Gafni, A., Steel, D. G., and Ramamoorthy, A. (2008). Amyloid fiber formation and membrane disruption are separate processes localized in two distinct regions of IAPP, the type-2-diabetes-related peptide. J. Am. Chem. Soc. 130, 6424-6429. doi: 10.1021/ja710484d

Cabaleiro-Lago, C., Szczepankiewicz, O., and Linse, S. (2012). The effect of nanoparticles on amyloid aggregation depends on the protein stability and intrinsic aggregation rate. Langmuir 28, 1852-1857. doi: 10.1021/la203078w

Cao, P., and Raleigh, D. P. (2012). Analysis of the inhibition and remodeling of islet amyloid polypeptide amyloid fibers by flavanols. Biochemistry 51, 2670-2683. doi: 10.1021/bi2015162

Cooper, G. J., Willis, A. C., Clark, A., Turner, R. C., Sim, R. B., and Reid, K. B. (1987). Purification and characterization of a peptide from amyloidrich pancreases of type-2 diabetic-patients. Proc. Natl. Acad. Sci. U.S.A. 84, 8628-8632. doi: 10.1073/pnas.84.23.8628

Da Ros, T., and Prato, M. (1999). Medicinal chemistry with fullerenes and fullerene derivatives. Chem. Commun. 8, 663-669. doi: 10.1039/a809495k

Daura, X., Gademann, K., Jaun, B., Seebach, D., van Gunsteren, W. F., and Mark, A. E. (1999). Peptide folding: when simulation meets experiment. Angew. Chem. Int. Ed. 38, 236-240. doi: 10.1002/(SICI)1521-3773(19990115)38:1/ $2<236:$ AID-ANIE236>3.0.CO;2-M 
Deng, Y., Qian, Z., Luo, Y., Zhang, Y., Mu, Y., and Wei, G. (2013). Membrane binding and insertion of a pHLIP peptide studied by allatom molecular dynamics simulations. Int. J. Mol. Sci. 14, 14532-14549. doi: $10.3390 /$ ijms 140714532

Dugan, L. L., Turetsky, D. M., Du, C., Lobner, D., Wheeler, M., Almli, C. R., et al. (1997). Carboxyfullerenes as neuroprotective agents (vol 94, pg 9434, 1997). Proc. Natl. Acad. Sci. U.S.A. 94, 12241-12241. doi: 10.1073/pnas.94.22.12241-a

Dupuis, N. F., Wu, C., Shea, J. E., and Bowers, M. T. (2009). Human islet amyloid polypeptide monomers form ordered beta-hairpins: a possible direct amyloidogenic precursor. J. Am. Chem. Soc. 131, 18283-18292. doi: $10.1021 /$ ja $903814 \mathrm{q}$

Dupuis, N. F., Wu, C., Shea, J. E., and Bowers, M. T. (2011). The amyloid formation mechanism in human IAPP: dimers have beta-strand monomer-monomer interfaces. J. Am. Chem. Soc. 133, 7240-7243. doi: 10.1021/ja1081537

Faridi, A., Sun, Y., Mortimer, M., Aranha, R. R., Nandakumar, A., Li, Y., et al. (2019). Graphene quantum dots rescue protein dysregulation of pancreatic beta-cells exposed to human islet amyloid polypeptide. Nano Res. 12, 2827-2834. doi: 10.1007/s12274-019-2520-7

Gazit, E. (2002). A possible role for pi-stacking in the self-assembly of amyloid fibrils. FASEB J. 16, 77-83. doi: 10.1096/fj.01-0442hyp

Gladytz, A., Abel, B., and Risselada, H. J. (2016). Gold-induced fibril growth: the mechanism of surface-facilitated amyloid aggregation. Angew. Chem. Int. Ed. 55, 11242-11246. doi: 10.1002/anie.201605151

Goldsbury, C., Goldie, K., Pellaud, J., Seelig, J., Frey, P., Müller, S. A., et al. (2000). Amyloid fibril formation from full-length and fragments of amylin. J. Struct. Biol. 130, 352-362. doi: 10.1006/jsbi.2000.4268

Guo, J., Li, J., Zhang, Y., Jin, X., Liu, H., and Yao, X. (2013). Exploring the influence of carbon nanoparticles on the formation of beta-sheet-rich oligomers of IAPP(2)(2)(-)(2)(8) peptide by molecular dynamics simulation. PLoS ONE 8:e65579. doi: 10.1371/journal.pone.0065579

Haataja, L., Gurlo, T., Huang, C. J., and Butler, P. C. (2008). Islet amyloid in type 2 diabetes, and the toxic oligomer hypothesis. Endocr. Rev. 29, 303-316. doi: 10.1210/er.2007-0037

Humphrey, W., Dalke, A., and Schulten, K. (1996). VMD: Visual molecular dynamics. J. Mol. Graph. Model. 14, 33-38. doi: 10.1016/0263-7855(96)00018-5

Jaikaran, E. T., Higham, C. E., Serpell, L. C., Zurdo, J., Gross, M., Clark, A., et al. (2001). Identification of a novel human islet amyloid polypeptide betasheet domain and factors influencing fibrillogenesis. J. Mol. Biol. 308, 515-525. doi: 10.1006/jmbi.2001.4593

Javed, I., He, J. C., Kakinen, A., Faridi, A., Yang, W., Davis, T. P., et al. (2019). Probing the aggregation and immune response of human islet amyloid polypeptides with ligand-stabilized gold nanoparticles. ACS Appl. Mater. Interfaces. 11, 10462-10471. doi: 10.1021/acsami.8b19506

Jiang, P., Xu, W., and Mu, Y. (2009). Amyloidogenesis abolished by proline substitutions but enhanced by lipid binding. PLoS Comput. Biol. 5:e1000357. doi: 10.1371/journal.pcbi.1000357

Kayed, R., Bernhagen, J., Greenfield, N., Sweimeh, K., Brunner, H., Voelter, W., et al. (1999). Conformational transitions of islet amyloid polypeptide (IAPP) in amyloid formation in vitro. J. Mol. Biol. 287, 781-796. doi: $10.1006 /$ jmbi.1999.2646

Ke, P. C., Pilkington, E. H., Sun, Y., Javed, I., Kakinen, A., Peng, G., et al. (2019). Mitigation of amyloidosis with nanomaterials. Adv. Mater. doi: 10.1002/adma.201901690. [Epub ahead of print].

Kim, D., Yoo, J. M., Hwang, H., Lee, J., Lee, S. H., Yun, S. P., et al. (2018). Graphene quantum dots prevent alpha-synucleinopathy in Parkinson's disease. Nat. Nanotechnol. 13, 812-818. doi: 10.1038/s41565-018-0179-y

Kim, J. E., and Lee, M. (2003). Fullerene inhibits beta-amyloid peptide aggregation. Biochem. Biophys. Res. Commun. 303, 576-579. doi: 10.1016/S0006-291X(03)00393-0

Lao, Z., Chen, Y., Tang, Y., and Wei, G. (2019). Molecular dynamics simulations reveal the inhibitory mechanism of dopamine against human islet amyloid polypeptide (hIAPP) aggregation and its destabilization effect on hIAPP protofibrils. ACS Chem. Neurosci. 10, 4151-4159. doi: 10.1021 acschemneuro.9b00393

Larson, J. L., and Miranker, A. D. (2004). The mechanism of insulin action on islet amyloid polypeptide fiber formation. J. Mol. Biol. 335, 221-231. doi: 10.1016/j.jmb.2003.10.045
Li, H., Luo, Y., Derreumaux, P., and Wei, G. (2011). Carbon nanotube inhibits the formation of beta-sheet-rich oligomers of the Alzheimer's amyloid-beta(16-22) peptide. Biophys. J. 101, 2267-2276. doi: 10.1016/j.bpj.2011.09.046

Luca, S., Yau, W. M., Leapman, R., and Tycko, R. (2007). Peptide conformation and supramolecular organization in amylin fibrils: constraints from solid-state NMR. Biochemistry 46, 13505-13522. doi: 10.1021/bi701427q

Maciel, C., Fileti, E. E., and Rivelino, R. (2011). Assessing the solvation mechanism of C-60(OH)(24) in aqueous solution. Chem. Phys. Lett. 507, 244-247. doi: 10.1016/j.cplett.2011.03.080

Mahmoudi, M., Kalhor, H. R., Laurent, S., and Lynch, I. (2013). Protein fibrillation and nanoparticle interactions: opportunities and challenges. Nanoscale 5, 2570-2588. doi: 10.1039/c3nr33193h

Marek, P., Abedini, A., Song, B. B., Kanungo, M., Johnson, M. E., Gupta, R., et al. (2007). Aromatic interactions are not required for amyloid fibril formation by islet amyloid polypeptide but do influence the rate of fibril formation and fibril morphology. Biochemistry 46, 3255-3261. doi: 10.1021/bi0621967

Mo, Y., Brahmachari, S., Lei, J., Gilead, S., Tang, Y., Gazit, E., et al. (2018). The inhibitory effect of hydroxylated carbon nanotubes on the aggregation of human islet amyloid polypeptide revealed by a combined computational and experimental study. ACS Chem. Neurosci. 9, 2741-2752. doi: 10.1021/acschemneuro.8b00166

Mo, Y., Lei, J., Sun, Y., Zhang, Q., and Wei, G. (2016). Conformational ensemble of hIAPP dimer: insight into the molecular mechanism by which a green tea extract inhibits hIAPP aggregation. Sci. Rep. 6:33076. doi: 10.1038/srep33076

Nadler, W., and Hansmann, U. H. (2008). Optimized explicit-solvent replica exchange molecular dynamics from scratch. J. Phys. Chem. B 112, 10386-10387. doi: $10.1021 /$ jp805085y

Nanga, R. P., Brender, J. R., Vivekanandan, S., and Ramamoorthy, A. (2011). Structure and membrane orientation of IAPP in its natively amidated form at physiological $\mathrm{pH}$ in a membrane environment. Biochim. Biophys. Acta Biomemb. 1808, 2337-2342. doi: 10.1016/j.bbamem.2011. 06.012

Nedumpully-Govindan, P., Gurzov, E. N., Chen, P. Y., Pilkington, E. H., Stanley, W. J., Litwak, S. A., et al. (2016). Graphene oxide inhibits hIAPP amyloid fibrillation and toxicity in insulin-producing NIT-1 cells. Phys. Chem. Chem. Phys. 18, 94-100. doi: 10.1039/C5CP05924K

Nielsen, J. T., Bjerring, M., Jeppesen, M. D., Pedersen, R. O., Pedersen, J. M., Hein, K. L., et al. (2009). Unique identification of supramolecular structures in amyloid fibrils by solid-state NMR spectroscopy. Angew. Chem. Int. Ed. Engl. 48, 2118-2121. doi: 10.1002/anie.200804198

Padrick, S. B., and Miranker, A. D. (2001). Islet amyloid polypeptide: identification of long-range contacts and local order on the fibrillogenesis pathway. J. Mol. Biol. 308, 783-794. doi: 10.1006/jmbi.2001.4608

Palhano, F. L., Lee, J., Grimster, N. P., and Kelly, J. W. (2013). Toward the molecular mechanism(s) by which EGCG treatment remodels mature amyloid fibrils. J. Am. Chem. Soc. 135, 7503-7510. doi: 10.1021/ja3115696

Pithadia, A., Brender, J. R., Fierke, C. A., and Ramamoorthy, A. (2016). Inhibition of IAPP aggregation and toxicity by natural products and derivatives. J. Diabetes Res. 2016:2046327. doi: 10.1155/2016/2046327

Podolski, I. Y., Podlubnaya, Z. A., Kosenko, E. A., Mugantseva, E. A., Makarova, E. G., Marsagishvili, L. G., et al. (2007). Effects of hydrated forms of C-60 fullerene on amyloid beta-peptide fibrillization in vitro and performance of the cognitive task. J. Nanosci. Nanotechnol. 7, 1479-1485. doi: 10.1166/jnn.2 007.330

Porat, Y., Mazor, Y., Efrat, S., and Gazit, E. (2004). Inhibition of islet amyloid polypeptide fibril formation: a potential role for heteroaromatic interactions. Biochemistry 43, 14454-14462. doi: 10.1021/bi048582a

Qi, R., Luo, Y., Ma, B., Nussinov, R., and Wei, G. (2014). Conformational distribution and alpha-Helix to beta-Sheet transition of human amylin fragment dimer. Biomacromolecules 15, 122-131. doi: 10.1021/bm401406e

Qiao, Q., Bowman, G. R., and Huang, X. (2013). Dynamics of an intrinsically disordered protein reveal metastable conformations that potentially seed aggregation. J. Am. Chem. Soc. 135, 16092-16101. doi: 10.1021/ja403147m

Qiao, Q., Qi, R., Wei, G., and Huang, X. (2016). Dynamics of the conformational transitions during the dimerization of an intrinsically disordered peptide: a case study on the human islet amyloid polypeptide fragment. Phys. Chem. Chem. Phys. 18, 29892-29904. doi: 10.1039/C6CP05590G 
Saunders, J. C., Young, L. M., Mahood, R. A., Jackson, M. P., Revill, C. H., Foster, R. J., et al. (2016). An in vivo platform for identifying inhibitors of protein aggregation. Nat. Chem. Biol. 12, 94-101. doi: 10.1038/nchembio. 1988

Schrodinger, L. L. C. (2015). The PyMOL Molecular Graphics System, Version 1.8. Schrödinger. Available online at: https://pymol.org/2/

Sugita, Y., and Okamoto, Y. (1999). Replica-exchange molecular dynamics method for protein folding. Chem. Phys. Lett. 314, 141-151. doi: 10.1016/S0009-2614(99)01123-9

Sumner, S. C., Fennell, T. R., Snyder, R. W., Taylor, G. F., and Lewin, A. H. (2010). Distribution of carbon-14 labeled C60 ([14C]C60) in the pregnant and in the lactating dam and the effect of 660 exposure on the biochemical profile of urine. J. Appl. Toxicol. 30, 354-360. doi: 10.1002/jat.1503

Sun, Y., Kakinen, A., Zhang, C., Yang, Y., Faridi, A., Davis, T. P., et al. (2019). Amphiphilic surface chemistry of fullerenols is necessary for inhibiting the amyloid aggregation of alpha-synuclein NACore. Nanoscale 11, 11933-11945. doi: 10.1039/C9NR02407G

Tsuchiya, T., Oguri, I., Yamakoshi, Y. N., and Miyata, N. (1996). Novel harmful effects of [60]fullerene on mouse embryos in vitro and in vivo. FEBS Lett. 393, 139-145. doi: 10.1016/0014-5793(96)00812-5

Wang, M., Sun, Y., Cao, X., Peng, G., Javed, I., Kakinen, A., et al. (2018). Graphene quantum dots against human IAPP aggregation and toxicity in vivo. Nanoscale 10, 19995-20006. doi: 10.1039/C8NR07180B

Weirich, F., Gremer, L., Mirecka, E. A., Schiefer, S., Hoyer, W., and Heise, H. (2016). Structural characterization of fibrils from recombinant human islet amyloid polypeptide by solid-state NMR: the central FGAILS segment is part of the beta-sheet core. PLOS ONE 11:e0161243. doi: 10.1371/journal.pone. 0161243

Xie, L., Luo, Y., Lin, D., Xi, W., Yang, X., and Wei, G. (2014). The molecular mechanism of fullerene-inhibited aggregation of Alzheimer's beta-amyloid peptide fragment. Nanoscale 6, 9752-9762. doi: 10.1039/C4NR01005A

$\mathrm{Xu}, \mathrm{W}$., Jiang, P., and Mu, Y. (2009). Conformation preorganization: effects of S20G mutation on the structure of human islet amyloid polypeptide segment. J. Phys. Chem. B 113, 7308-7314. doi: 10.1021/jp8106827

Yan, L. M., Tatarek-Nossol, M., Velkova, A., Kazantzis, A., and Kapurniotu, A. (2006). Design of a mimic of nonamyloidogenic and bioactive human islet amyloid polypeptide (IAPP) as nanomolar affinity inhibitor of IAPP cytotoxic fibrillogenesis. Proc. Natl. Acad. Sci. U.S.A. 103, 2046-2051. doi: 10.1073/pnas.0507471103

Young, L. M., Saunders, J. C., Mahood, R. A., Revill, C. H., Foster, R. J., Tu, L. H., et al. (2015). Screening and classifying small-molecule inhibitors of amyloid formation using ion mobility spectrometry-mass spectrometry. Nat. Chem. 7, 73-81. doi: 10.1038/nchem.2129

Zhang, S., Andreasen, M., Nielsen, J. T., Liu, L., Nielsen, E. H., Song, J., et al. (2013). Coexistence of ribbon and helical fibrils originating from hIAPP(2029) revealed by quantitative nanomechanical atomic force microscopy. Proc. Natl. Acad. Sci. U.S.A. 110, 2798-2803. doi: 10.1073/pnas.1209 955110

Zhao, D. S., Chen, Y. X., and Li, Y. M. (2015). Rational design of an orthosteric regulator of hIAPP aggregation. Chem. Commun. 51, 2095-2098. doi: 10.1039/C4CC06739H

Zhou, X., Xi, W., Luo, Y., Cao, S., and Wei, G. (2014). Interactions of a watersoluble fullerene derivative with amyloid-beta protofibrils: dynamics, binding mechanism, and the resulting saltbridge disruption. J. Phys. Chem. B 118, 6733-6741. doi: 10.1021/jp503458w

Zhu, X. S., Zhu, L., Li, Y., Duan, Z. H., Chen, W., and Alvarez, P. J. J. (2007). Developmental toxicity in zebrafish (Danio rerio) embryos after exposure to manufactured nanomaterials: buckminsterfullerene aggregates (nC(60)) and fullerol. Environ. Toxicol. Chem. 26, 976-979. doi: 10.1897/0 6-583.1

Conflict of Interest: The authors declare that the research was conducted in the absence of any commercial or financial relationships that could be construed as a potential conflict of interest.

Copyright (c) 2020 Bai, Lao, Chen, Tang and Wei. This is an open-access article distributed under the terms of the Creative Commons Attribution License (CC BY). The use, distribution or reproduction in other forums is permitted, provided the original author(s) and the copyright owner(s) are credited and that the original publication in this journal is cited, in accordance with accepted academic practice. No use, distribution or reproduction is permitted which does not comply with these terms. 